\title{
Learning Styles as Predictors of Classroom Dialogue Among Upper Basic Science Students in Taraba State, Nigeria
}

\author{
Christina Tanko Audu \\ Department of Integrated Science, College of Education, Zing, Taraba State, Nigeria
}

\begin{abstract}
The study investigated if learning styles are predicators of classroom dialogue among upper basic students in basic science in Taraba State, Nigeria. The sample of this study was made up of 392 UBE3 students that were drawn from 14 upper basic schools. This study adopted the correlational research design. The instrument known as Learning Styles Preference Questionnaire (LSPQ) and Classroom Dialogue Scale (CDS) was used to collect data for this study. LSPQ and CDS were trial tested which yielded the reliability values of 0.87 and 0.79 using Cronbach Alpha respectively. Five research questions and five null hypotheses guided the study. The research questions were answered using multiple regression analysis while, the hypotheses were tested using ANOVA of regression analysis. The study revealed among other that there is significant relationship between visual learning style and classroom dialogue $\left[\mathrm{F}_{1,129}=0.197 ; \mathrm{p}<0.05\right]$. There is no significant relationship between auditory learning style and classroom dialogue $\left[\mathrm{F}_{1,107}=0.142 ; \mathrm{p}>0.05\right]$. There is significant relationship between visual, auditory, readingwriting, kinesthetic learning style and classroom dialogue $\left[\mathrm{F}_{4,391}=3.101 ; \mathrm{p}<0.05\right]$. It was recommended among that students should be encouraged as they adopt visual and kinesthetic learning styles in order to enhance their learning and classroom dialogue. Education stakeholders should organize conferences to encourage basic science teachers to adopt visual and kinesthetic learning styles in teaching in order to enhance classroom dialogue.
\end{abstract}

Keywords: Learning styles, classroom dialogue, and Basic Science.

DOI: $10.7176 / \mathrm{JEP} / 11-11-04$

Publication date: April $30^{\text {th }} 2020$

\section{Introduction}

Basic Science is the bedrock to future understanding of advanced studies in science, technology and engineering. The overall objectives of Basic Science, as stated in the Basic Science Curriculum developed by the Nigerian Educational Research and Development Council (NERDC, 2007) are to enable the learners to: acquire and apply basic knowledge and skills in science and technology to meet societal needs; and providing a reasonable and adequate foundation for a secondary school science course. It is therefore necessary that students studying basic science should understand the subject so that they can apply the knowledge to everyday interactions with people and the ever changing environment. The researchers observed that, as promising as the aims and objectives of Basic Science curriculum is, the classroom dialogue of students offering Basic Science is still remain poor in Nigeria which in turn affect students approach the diversity of the world in an open-minded way. Participation in dialogue drives students to acquire and practise higher level thinking skills and to honestly and respectfully engage with a range of viewpoints. It is acknowledged that learning is most effective when students are engaged in cognitive restructuring of their own understanding and knowledge through dialogue that allows them to reflect on their thinking (Wells, 2013).

\section{Background to the study}

Thus, classroom dialogue is crucial for effective pedagogy. One of the most essential goals and greatest challenges of science educators is to create a learning environment in which the learners participate actively in teaching and learning process through classroom interaction or dialogue (Ajayi, 2019). By implication, for students to participate actively in classroom, there is need to actively engage students in substantive dialogue. Classroom dialogue is where one individual addresses another individual or individuals and at least one addressed individual replies (Howe, 2012). Classroom dialogue can be called "shared thinking" in which the participants are open to one another's ideas and seek to reach understanding of each other (Phillipson \& Wegerif, 2017). Dialogue between teacher and students or among students contributes to students' development (Seidel, 2015), and skills for dialogue and shared knowledge building can impact students' lifelong learning and the quality and meaningfulness of their lives (Rasku-Puttonen, 2018).

It is important that students have the opportunity to practice speaking clearly and confidently, explaining their own point of view, beliefs or values. When learners take part in dialogue it is important to remember that they are not just learning from others but, at the same time, they are also responsible for teaching themselves. Classroom dialogue is essential not because any verbal address reply interaction around curricular material is viewed as valuable. Rather, it is widely believed that there are ways of organizing classroom dialogue, which, if achieved, will prove beneficial as regards educational goals. Yet even if numerous practices are ordinarily regarded as dialogic, there has long been a sense of rarity in classrooms. The researcher observes that, though classroom 
activity is dominated by verbal communication but stresses that such communication is primarily teacher delivery without effective teacher-student and student-student dialogue.

Despite the importance and benefits of classroom dialogue, this kind of discussion is rare in the classrooms. Especially in whole-class situations, discussions typically consist of teacher-centred or controlled talk through scripted patterns. In any event, student participation is not equally distributed around the classroom, but heavily dependent on such factors as gender, and learning styles. The researcher observes that learning styles may affect classroom dialogue. Tzu-Ling and Yi-Kuan (2015) define learning styles as ways or methods that the individual acquire and process information. Ossai (2012) sees learning style as the method that the individual has come to get used to for acquiring, processing and storing new information and skills. In other words, learning style represents the approach to the learning process and his/her general attitude. Scientists and psychologists have developed different models such as VARK model to understand the different ways that people learn best. VARK model identifies four primary types of learning styles which includes visual, auditory, reading/writing, and kinesthetic learning styles. The visual learners learn best by looking at graphics, watching a demonstration, or reading. For them, it's easy to look at charts and graphs, but they may have difficulty focusing while listening to an explanation.

The auditory learners would rather listen to things being explained than read about them. Reciting information out loud and having music in the background may be a common study method. The kinesthetic learners on the other hand process information best through a "hands-on" experience. Actually doing an activity can be the easiest way for them to learn. Sitting still while studying may be difficult, but writing or drawing things down makes it easier for them to understand. According to Murat (2013), learning styles such as diverging, assimilation, converging and accommodating could also fall under visual, auditory and kinesthetic or tactile learners. The learning styles determine the level of students' interaction with the learning mediums which may affect classroom dialogue. By implication, the level of teacher-student and student-student classroom dialogue may be associated with learning styles. Doveston (2013) revealed that employing dialogic practices like active listening and cooperative activities, students' social and listening skills improved.

\section{Statement of the problem}

Classroom dialogue should fulfill certain prerequisites to support students' learning and benefit students' shared knowledge building. Observed high-quality teacher-student dialogue and teaching practices have been shown to enhance students' motivation to learn (Lerkkanen, 2012; Pakarinen, 2013), and contribute to their academic and social development (Guedes, 2016). Aliu (2017) found that learning style influence students' communicative competence. In addition, dialogic teaching in elementary science lessons has been shown to create varied opportunities for discursive identity negotiation among students (Kumpulainen \& Rajala, 2015). The researchers observed that classroom dialogue may be associated with their learning styles. However, it is scarcity of study to clearly show if learning styles have any correlation with classroom dialogue. Poor classroom dialogue is likely to be associated with the kind learning styles which in turn affect the students' ability to develop their own understanding and knowledge. In response to this problem, this study investigated if learning styles adopted has any correlation with classroom dialogue among Basic Science students in upper basic schools in Taraba State, Nigeria.

\section{Research Questions}

The following research questions guided this study:

1. What is the relationship between visual learning style and classroom dialogue of students offering Basic Science in upper basic schools?

2. What is the relationship between auditory learning style and classroom dialogue of students offering Basic Science in upper basic schools?

3. What is the relationship between reading-writing learning style and classroom dialogue students of offering Basic Science in upper basic schools?

4. What is the relationship between kinesthetic learning style and classroom dialogue of students offering Basic Science in upper basic schools?

5. What is the relationship between the combination of visual, auditory, reading-writing, kinesthetic learning styles and classroom dialogue of students offering Basic Science in upper basic schools?

\section{Hypotheses}

The following null hypotheses were tested:

1. There is no significant relationship between visual learning style and classroom dialogue of students offering Basic Science in upper basic schools.

2. The relationship between auditory learning style and classroom dialogue of students offering Basic 
Science in upper basic schools is not statistically significant.

3. There is no significant relationship between reading-writing learning style and classroom dialogue of students offering Basic Science in upper basic schools.

4. There is no significant relationship between kinesthetic learning style and classroom dialogue of students offering Basic Science in upper basic schools.

5. The relationship between the combination of visual, auditory, reading-writing, kinesthetic learning styles and classroom dialogue of students offering Basic Science in upper basic schools is not statistically significant.

\section{Research Design and Procedure}

This study adopted the correlational research design. This type of study seeks to establish what relationship exists between two or more variables. Correlational design was considered suitable for this study because the researcher was seeking to establish a relationship between the independent variable (Learning Styles) and the dependent variables (Classroom dialogue). The study area was Taraba State, Nigeria. The population of the study comprised all the 19,851 Upper Basic III students in public upper basic schools in the 16 Local Government Areas of Taraba State (Taraba State Ministry of Education, 2019). The sample of this study was made up of 392 Upper Basic three (UBE3) students offering Basic Science that were drawn from 14 upper basic schools. In each of these 14 sampled schools, 28 UBE3 students offering Basic Science were selected. A multi-stage sampling technique was used in the study.

The instrument known as Learning Styles Preference Questionnaire (LSPQ) and Classroom Dialogue Scale (CDS) were used to collect data for this study. The LSPQ items cut across four learning styles namely; visual, auditory, reading-writing and kinesthetic learning styles. While, CDS items is divided into four sub-sections based on the four learning styles. Sections A contains items on classroom dialogue that may be predicted by visual skills, section B contains items on classroom dialogue that may be predicted by auditory skills, section C contains items on contains items on classroom dialogue that may be predicted by writing and reading skills and section D contains items on classroom dialogue that may be predicted by hands-on or doing skills. Both the LSPQ and CDS are researcher constructed questionnaires based on what the researcher considered as useful and relevant information obtained from relevant literatures reviewed in the study.

Both Learning Styles Preference Questionnaire (LSPQ) and Classroom Dialogue Scale (CDS) items have four Likert-type options of Strongly Agreed (SA), Agreed (A), Disagreed (D) and Strongly Disagreed (SD). LSPQ and CDS is a 32-item questionnaire respectively bordering on the students' learning styles and classroom dialogue. The respondents were instructed to place a tick in the column with the response option that is appropriate to their opinion. For all items the scores are 4 for SA, 3 for A, 2 for D and 1 for SD for positive items and reversed for negative items. That is, SA-1, A- 2, D-3 and SD-4. Both LSPQ and CDS generated information on the preferred learning styles and classroom dialogue respectively. The mean of every respondent in each learning style will be calculated separately and the learning style in which the respondent scores the highest mean was considered as the respondent's preferred learning style. Meanwhile, The CDS was used to measure students offering Basic Science the level of classroom dialogue.

The content validity of the instruments was carried out by four experts. Three expert from Science Education and one lecturer who is knowledgeable in measurement and evaluation, all from the Department of Science and Mathematics Education, Benue State University, Makurdi. To determine the reliability of the instruments, a trial test was conducted by the researcher. Sixty upper basic III students from two upper basic schools which are not part of the sample for the main study were used for the trial test. Cronbach Alpha was used to estimate the reliability coefficients of the instruments which yielded a coefficient value of 0.87 and 0.79 respectively. Two research assistants were briefed to assist the researcher in administering copies of the questionnaires. The face to face method was used in the distribution of 392 copies of the questionnaire. To avoid missing copies of the questionnaire, the questionnaires were given to the respondents and collected by the research assistants the same day. The research questions were answered using multiple regression analysis while, the null hypotheses for the study were also tested using ANOVA of regression analysis to investigate the extent to which learning styles account for classroom dialogue of students offering Basic Science in upper basic schools in Taraba State, Nigeria.

\section{Results}

\section{Research question one}

What is the relationship between visual learning style and classroom dialogue of students offering Basic Science in upper basic schools? The answer to research question one is contained in Table 1.

Table 1: Regression Analysis of Visual Learning Style and Classroom Dialogue

\begin{tabular}{cccccc}
\hline Model & R & R Square & Adjusted R Square & Std. Error of the Estimate & Durbin-Watson \\
\hline 1 & $.172^{\mathrm{a}}$ & .434 & .197 & 14.003 & 2.875 \\
\hline
\end{tabular}

Table 1 shows the regression analysis of the relationship between students' visual learning style and 
classroom dialogue of students offering Basic Science in upper basic schools. The results imply that the correlation between students' visual learning style and their classroom dialogue in Basic Science is 0.172 with a coefficient of determination of 0.434 . This means that 43.4 percent variation of the students' classroom dialogue can be accounted for by their visual learning styles.

\section{Research question two}

What is the relationship between auditory learning style and classroom dialogue of students offering Basic Science in upper basic schools? The answer to research question two is contained in Table 2.

Table 2: Regression Analysis of Auditory Learning Style and Classroom Dialogue

\begin{tabular}{cccccc}
\hline Model & R & R Square & Adjusted R Square & Std. Error of the Estimate & Durbin-Watson \\
\hline 1 & $.151^{\mathrm{a}}$ & .514 & .167 & 9.163 & 1.002 \\
\hline
\end{tabular}

Table 2 shows the regression analysis of the relationship between students' auditory learning style and classroom dialogue of students offering Basic Science in upper basic schools. The result indicated that the correlation between students' auditory learning style and their classroom dialogue of Basic Science is .151 with a coefficient of determination of 0.514 . This means that 51.4 percent variation of the students' classroom dialogue can be accounted for by their auditory learning styles.

\section{Research question three}

What is the relationship between reading-writing learning style and classroom dialogue students of offering Basic Science in upper basic schools? The answer to research question three is contained in Table 3.

Table 3: Regression Analysis of Reading-Writing Learning Style and Classroom dialogue

\begin{tabular}{lccccc}
\hline Model & R & R Square & Adjusted R Square & Std. Error of the Estimate & Durbin-Watson \\
\hline 1 & $.121^{\mathrm{a}}$ & .012 & .13 & 9.010 & 1.411 \\
\hline
\end{tabular}

Table 3 shows the regression analysis of the relationship between students' reading-writing learning style and classroom dialogue of students offering Basic Science in upper basic schools. The results imply that the correlation between students' reading-writing learning style and their classroom dialogue in Basic Science is 0.121 with a coefficient of determination of 0.012 . This means that only 1.2 percent variation of the students' classroom dialogue can be attributed to their reading-writing learning styles.

\section{Research question four}

What is the relationship between kinesthetic learning style and classroom dialogue of students offering Basic Science in upper basic schools? The answer to research question four is contained in Table 4.

Table 4: Regression Analysis of Kinesthetic Learning Style and Classroom Dialogue

\begin{tabular}{lccccc}
\hline Model & R & R Square & Adjusted R Square & Std. Error of the Estimate & Durbin-Watson \\
\hline 1 & $.135^{\mathrm{a}}$ & .661 & .210 & 14.051 & 2.453 \\
\hline
\end{tabular}

Table 4 shows the regression analysis of the relationship between students' kinesthetic learning style and classroom dialogue of students offering Basic Science in upper basic schools. The result indicate that the correlation between students' kinesthetic learning style and their classroom dialogue in Basic Science is 0.135 with a coefficient of determination of 0.661 meaning that 66.1 percent variation of the students' classroom dialogue can be attributed to their kinesthetic learning styles.

\section{Research question five}

What is the relationship between the combination of visual, auditory, reading-writing, kinesthetic learning styles and classroom dialogue of students offering Basic Science in upper basic schools? The answer to research question five is contained in Table 5.

Table 5: Regression Analysis of Visual, Auditory, Reading-Writing, Kinesthetic Learning Style and Classroom Dialogue

\begin{tabular}{lccccc}
\hline Model & R & R Square & Adjusted R Square & Std. Error of the Estimate & Durbin-Watson \\
\hline 4 & $.431^{\mathrm{e}}$ & .572 & .373 & 10.090 & 1.724 \\
\hline
\end{tabular}

Table 5 shows the regression analysis of the relationship between students' visual, auditory, reading-writing, kinesthetic learning style and classroom dialogue of students offering Basic Science in upper basic schools. The results imply that the correlation between students' visual, auditory, reading-writing, kinesthetic learning style and their classroom dialogue in Basic Science is 0.431 with a coefficient of determination of 0.572 . This means that 57.2 percent variation of the students' classroom dialogue can be attributed to the combination of visual, auditory, reading-writing, kinesthetic learning style learning styles.

\section{Hypothesis one}

There is no significant relationship between visual learning style and classroom dialogue of students offering Basic Science in upper basic schools. The test to hypothesis one is presented in Table 6. 
Table 6: Analysis of Variance of Visual Learning Style and Classroom Dialogue

\begin{tabular}{llccccl}
\hline Model & & Sum of Squares & df & Mean Square & F & Sig. \\
\hline 1 & Regression & 51.002 & 1 & 51.002 & .197 & $.001^{\mathrm{b}}$ \\
& Residual & 22377.050 & 128 & 149.009 & & \\
& Total & 22428.052 & 129 & & & \\
\hline
\end{tabular}

ANOVA of regression analysis result in Table 6 reveals that there is a significant relationship between visual learning style and classroom dialogue of students offering Basic Science in upper basic schools $\left[\mathrm{F}_{1,129}=0.197 ; \mathrm{p}\right.$ $<0.05]$. The null hypothesis is therefore rejected. This implies that visual learning style has significant relationship with classroom dialogue of students offering Basic Science in upper basic schools in Taraba State, Nigeria.

\section{Hypothesis two}

The relationship between auditory learning style and classroom dialogue of students offering Basic Science in upper basic schools is not statistically significant. The test to hypothesis two is presented in Table 7.

Table 7: Analysis of Variance of Auditory Learning Style and Classroom Dialogue

\begin{tabular}{llrrrrl}
\hline Model & & Sum of Squares & df & Mean Square & F & Sig. \\
\hline 1 & Regression & 44.001 & 1 & 44.001 & .142 & $.125^{\mathrm{b}}$ \\
& Residual & 27790.298 & 106 & 107.080 & & \\
& Total & 27834.299 & 107 & & & \\
\hline
\end{tabular}

ANOVA of regression analysis result in Table 7 reveals that there is no significant relationship between auditory learning style and classroom dialogue of students offering Basic Science in upper basic schools $\left[\mathrm{F}_{1,107}=\right.$ $0.142 ; \mathrm{p}>0.05]$. The null hypothesis is therefore not rejected. This implies that auditory learning style has no significant relationship with classroom dialogue of students offering Basic Science in upper basic schools in Taraba State, Nigeria.

\section{Hypothesis three}

There is no significant relationship between reading-writing learning style and classroom dialogue of students offering Basic Science in upper basic schools. The test to hypothesis three is presented in Table 8 .

Table 8: Analysis of Variance of Reading-Writing Learning Style and Classroom Dialogue

\begin{tabular}{llcrrrr}
\hline Model & & Sum of Squares & df & Mean Square & F & Sig. \\
\hline 1 & Regression & 395.010 & 1 & 395.010 & 2.011 & $.102^{\mathrm{b}}$ \\
& Residual & 15669.303 & 103 & 104.060 & & \\
& Total & 16064.313 & 104 & & & \\
\hline
\end{tabular}

ANOVA of regression analysis result in Table 8 reveals that there is no significant relationship between reading-writing learning style and classroom dialogue of students offering Basic Science in upper basic schools $\left[\mathrm{F}_{1,104}=2.011 ; \mathrm{p}>0.05\right]$. The null hypothesis is therefore not rejected. This implies that no significant relationship between reading-writing learning and classroom dialogue of students offering Basic Science in upper basic schools in Taraba State, Nigeria

\section{Hypothesis four}

There is no significant relationship between kinesthetic learning style and classroom dialogue of students offering Basic Science in upper basic schools. The test to hypothesis four is presented in Table 9.

Table 9: Analysis of Variance of Kinesthetic Learning Style and Classroom Dialogue

\begin{tabular}{llclccc}
\hline Model & & Sum of Squares & df & Mean Square & F & Sig. \\
\hline 1 & Regression & 76.022 & 1 & 76.022 & .231 & $.000^{\mathrm{b}}$ \\
& Residual & 10091.907 & 62 & 162.773 & & \\
& Total & 10167.929 & 63 & & & \\
\hline
\end{tabular}

ANOVA of regression analysis result in Table 9 reveals that there is no significant relationship between kinesthetic learning style and classroom dialogue of students offering Basic Science in upper basic schools $\left[\mathrm{F}_{1,63}\right.$ $=0.231 ; \mathrm{p}<0.05]$. The null hypothesis is therefore rejected. This implies that there is significant relationship between kinesthetic learning style and classroom dialogue of students offering Basic Science in upper basic schools.

\section{Hypothesis five}

The relationship between the combination of visual, auditory, reading-writing, kinesthetic learning styles and classroom dialogue of students offering Basic Science in upper basic schools is not statistically significant. The test to hypothesis five is presented in Table 10. 
Table 10: Analysis of Variance of the Combination of Visual, Auditory, Reading-Writing, Kinesthetic Learning Style and Classroom Dialogue

\begin{tabular}{llrrrrr}
\hline Model & & Sum of Squares & df & Mean Square & F & Sig. \\
\hline 4 & Regression & 3640.614 & 4 & 910.035 & 3.101 & $.000^{\mathrm{f}}$ \\
& Residual & 5465.008 & 58 & 137.332 & & \\
& Total & 9105.622 & 391 & & & \\
\hline
\end{tabular}

ANOVA of regression analysis result in Table 10 reveals that the relationship the combination of visual, auditory, reading-writing, kinesthetic learning styles and classroom dialogue of students offering Basic Science in upper basic schools is statistically significant $\left[\mathrm{F}_{4,391}=3.101 ; \mathrm{p}<0.05\right]$. The null hypothesis is therefore rejected. This implies that there is significant relationship between the combination of visual, auditory, reading-writing, kinesthetic learning styles and classroom dialogue of students offering Basic Science in upper basic schools in Taraba State, Nigeria.

\section{Discussion of findings}

The study investigated learning styles as predictors of classroom dialogue among upper basic students offering Basic Science in Taraba State, Nigeria. The findings revealed that there is significant relationship between visual learning style and classroom dialogue of students offering Basic Science in upper basic schools. This implies that visual learning style is an individual determinant of classroom dialogue of students offering Basic Science in upper basic schools. The findings agree with that of Phillipson and Wegerif (2017) that there is a significant relationship between learning style of students and their performance in English language. The likely explanation for this outcome may be connected to the fact that visual learning style encourages students' interaction and help them to see what they are expected to know through visual aids that represent ideas using methods other than words, such as graphs, charts, diagrams, and symbols.

The findings revealed that there is no significant relationship between auditory learning style and classroom dialogue of students offering Basic Science in upper basic schools. This implies that auditory learning style is not an individual determinant of effective classroom dialogue of students in upper basic schools. The findings agree with the findings of Kumpulainen and Rajala (2015) who revealed that students auditory learning style have negative influence on students' classroom interaction. However, the findings disagree with that of Seidel (2016) that auditory learning style had significant relationship with students' academic performance. The likely explanation for this outcome may be connected to the fact that in auditory style students learn best through listening without necessary interacting with each other.

Another major finding of this present study is that there is no significant relationship between reading-writing learning style and classroom dialogue of students offering Basic Science in upper basic schools. This implies that reading-writing learning style is not an individual determinant of classroom dialogue of students in upper basic schools. The likely explanation for this outcome may be connected to the fact that in reading-writing learning style individuals are able to absorb and retain the most information through reading and writing text, versus imagery and symbolism without necessary having any dialogue with the teacher or other students. In reading-writing learning style students only learn by reading/writing learners are through reading lecture notes, writing essays, reading through textbooks and writing notes.

The findings also revealed that there is significant relationship between kinesthetic learning style and classroom dialogue of students in upper basic schools. This means that kinesthetic learning style is an individual determinant of classroom dialogue of students offering Basic Science in upper basic schools. The findings agree with that of Brown, Terry and Kelsey (2013) that kinesthetic learning style influence students communication skills in English language when comparing mean those in auditory learning style. In the same vein, the findings also agree with that of Howe (2012) kinesthetic learning style enhances students' academic performance in physics. The likely explanation for this outcome may be connected to the fact that kinesthetic learning style encourages students' active participation and dialogue because in kinesthetic style students learn via experience and doing in a collaborative setting which in turn enhances students dialogue in classroom. The findings also revealed that there is no significant relationship between visual, auditory, reading-writing, kinesthetic learning style and classroom dialogue of students offering Basic Science. The implication of the finding is that, some of variables such as auditory and reading-writing learning styles are not predicators of classroom dialogue; the combination of the variables are determinant of classroom dialogue of students in Basic Science. The findings however, disagree with that of Ibe (2012) who also found that there is a significant relationship between learning styles and academic performance.

\section{Conclusion}

It is evident from the findings of this study that auditory and reading-writing styles are not predictors of classroom dialogue. While, visual and kinesthetic styles are determinant of classroom dialogue of students offering Basic Science in Taraba State, Nigeria. This implies that teachers and students should adopt visual and kinesthetic 
learning styles to enhance classroom dialogue.

\section{Recommendations}

Based on the findings, the following recommendations were made:

1. Teachers should adopt visual and kinesthetic styles in teaching basic science in order to enhance classroom dialogue

2. Education stakeholders should organize conferences to encourage basic science teachers to adopt visual and kinesthetic learning styles in teaching in order to enhance classroom dialogue.

3. Students should be encouraged as they adopt visual and kinesthetic learning styles in order to enhance their learning and classroom dialogue.

\section{REFERENCES}

Ajayi, V.O. (2019). Improving senior secondary students' self-efficacy belief in organic chemistry using Kolb's and 5E learning models. Journal of Education Benue State University Makurdi, 18(2), 219-230.

Aliu, J. (2017). Scaffolding in teacher-student interaction: A decade of research. Educational Psychology Review, 22(2), 200-209.

Brown, N. R., Terry, R., \& Kelsey, D. K. (2013). The impact of learning styles on students' attitude towards mathematics. Journal of Agricultural Education, 54(4), 206-220.

Doveston, M. (2013). Developing capacity for social and emotional growth: An action research project. Pastoral Care in Education, 25(2), 46-54.

Guedes, R. (2016). Cooperative learning: Review of research and practice. Australian Journal of Teacher Education, 41(3), 39-54.

Howe, C. (2012). Classroom dialogue: A systematic review across four decades of research. Cambridge Journal of Education, 43(3), 325-356.

Ibe, H.N. (2012). Effects of learning styles on the performances of senior secondary school biology students. An International Multidisciplinary Journal, Ethiopia, 9(1), 214-227.

Kumpulainen, M., \& Rajala, J. (2015). Promoting teacher scaffolding in small-group work: A contingency perspective. Teaching and Teacher Education, 28(2), 193-205.

Lerkkanen, M.K., (2012). Dialogic teaching: Discussing theoretical contexts and reviewing evidence from classroom practice. Language and Education, 22(1), 222-240.

Murat, G. (2013). The effect of students' learning styles to their academic success. Creative Education, 4(10), $627-632$

National Education Research and Development Council (2007). 9-year curriculum for Basic Science. Abuja: NERDC Press.

Ossai, R. (2012). Learning styles: concepts and evidence. Academic Excellence Publishers.

Pakarinen, K.P. (2013). Cooperative learning: Review of research and practice. Australian Journal of Teacher Education, 41(3), 39-54.

Phillipson, N., \& Wegerif, R. (2017). Dialogic education: Mastering core concepts through thinking together. Routledge Press.

Rasku-Puttonen, H. (2018). Dialogical patterns of interaction in preschool classrooms. International Journal of Educational Research, 53(3), 138-149.

Seidel, R. K. (2015). Group genius: The creative power of collaboration. Basic Books.

Taraba State Ministry of Education (2019). Statistics unit reports on students' enrolment. Taraba State Ministry of Education.

Tzu-Ling, W., \& Yi-Kuan, T. (2015). Do thinking styles matter for science achievement and attitudes toward science class in male and female elementary school students in Taiwan? International Journal of Science and Mathematics Education, 13(4), 515-533.

Wells, G. (2013). "Who we become depends on the company we keep and on what we do and say together". International Journal of Educational Research, 46 (3\&4), 100-108. 